\title{
Smart Irrigation and Precision Farming of Paddy Field using Unmanned Ground Vehicle and Internet of Things System
}

\author{
Srinivas $A^{1}$ \\ Department of Mechanical Engineering \\ PES University \\ Bengaluru, India
}

\author{
J Sangeetha $^{2}$ \\ Department of Computer Science and Engineering \\ M S Ramaiah Institute of Technology \\ Bengaluru, India
}

\begin{abstract}
Paddy is one of the largest consumed staple foods across the globe, especially in Asian countries. With the population growing larger and the agricultural land shrinking, there is a need to increase the yield of the crop to meet the evergrowing food demand. The yield of paddy largely depends on the irrigation of the paddy field, that is maintaining the optimum water level in the paddy field. The solution to this irrigation problem has been proposed in this paper, by addressing various challenges in implementing the Unmanned Ground Vehicle (UGV) and Internet of Things (IoT) system in paddy cultivation. A UGV which carries the sensors were used to collect the sensor data (water level, rainwater, humidity, temperature, light intensity) from the paddy field, which is controlled by cloudbased solution and by the mobile application-based solution. The data was then processed and used to control the water valves which can again be controlled by using cloud and mobile application. Water level maintained by using the mobile application-based solution, cloud-based solution and by following the traditional method of irrigation was compared and the cloudbased solution was found to be more efficient. Thereby providing a solution which reduces the manpower required for the process of irrigation when compared to the traditional irrigation method, also reducing the water wastage, therefore conserving water.
\end{abstract}

Keywords-Sensor; cloud; mobile application; agriculture; water valve

\section{INTRODUCTION}

The Internet of Things (IoT) has entered almost all the areas in today's world. The concept of one thing being connected to other things. The ability to work with coordination, by communicating with one another over the Internet, has found a lot of application in fields like industry [1], smart city [2], connected building and campuses [3], smart home [4], health care [5], logistics [6], connected car [7]. Many research works are being done in various fields and domains [8], one of the fields where extensive research is being done is in agriculture [9].

The ever-growing population of the world, the diminishing natural resources, the depleting water resources has made food security a global concern. With only $11 \%$ of the earth surface [10] available for feeding 7.7 billion people across the globe [11], there is a need to implement new technologies in the field of agriculture. The leading food crops in terms of global consumption are paddy, wheat, and corn. Paddy is the most consumed, about an average of $50 \%$ of the daily caloric supply in Asian countries such as India, China, Indonesia, Japan, Philippines, Thailand etc. [12]. With urbanization, there is a competition for water sharing between cities, industries, and agriculture. It is estimated by [13] that the production of paddy must be increased by 50 to 60 per cent without increasing the land and water usage for paddy for the next 30 years. With many of the country economy depending mainly on paddy production, there is a need to implement innovations in the field of agriculture to cope up with all these challenges. The business data platform Statistica [14] estimates that about 3.8 billion people across the globe will have access to mobile phones and Internet by 2021, the use of Internet of thing can be the game-changer to boost the paddy production for all the developing nations.

Robots are machines that perform certain tasks and are usually controlled by a computer program. There are various kinds of robots such as autonomous robots (Robots which have central processing unit and can perform set of tasks on their own) and remote-controlled robots (Robots which are instructed by humans using a remote to perform tasks). Robots can also be classified into Unmanned Ariel Vehicle (UAV) and Unmanned Ground Vehicle (UGV) based on whether the unmanned robot moves in the air and moves on land respectively. Robots have entered agriculture to help farmers in various repetitive tasks or tasks that are difficult to be performed by humans. They are already being tested on applications such as spraying fungicides [15], pesticides [16], they are also used in mushroom picking [17]. There has been widespread research across the globe on robotics, with rapid research and development of robots, the markets will exhibit rapid growth during the coming decades [18].

\section{LITERATURE REVIEW}

The major factor influencing the yield of any crop is irrigation. In the paddy field, to increase the yield it is required to maintain standing water throughout the growth period, so the main aspect of irrigation system is maintaining the water level in the paddy field to the optimal level at all times [19]. Lots of IoT solutions has been developed by researchers across the globe for smart irrigation systems. One of them being the Wireless Sensor Networks (WSN) used in [20] where several sensor nodes are placed in various locations of the agricultural 
land and the soil moisture, temperature, humidity, and various other parameters are being measured. The Same concept of WSN was used in [21] to obtain temperature, humidity, phosphorous, nitrogen, calcium, soil temperature, moisture, and PH data in the sugarcane field. In [22] two different types of wireless sensor network were used to obtain real-time data for irrigation in nurseries, the wireless sensor network can be used in all the above-mentioned field. It can also be used in paddy cultivation as in [23] where wireless sensor network was utilized to monitor and irrigate the paddy field. This may lead to additional work thereby increasing the cost of production as the wireless sensors have to be removed from its place each time when heavy machinery is used for various activities in the paddy field.

The novelty of this paper is in developing a reliable solution for paddy cultivation using IoT system by investigating the problems in placing the sensor to monitor the paddy field. Due to harsh environmental conditions in the paddy field, like very loose soil, the constant presence of water etc. It is very difficult to employ the method of using multiple sensor nodes to monitor the soil state. Placing multiple sensor nodes will be very difficult for the sensor to be maintained properly in the harsh condition of the constantly wet paddy field. It would also cause a lot of difficulties while harvesting the paddy field because the sensors must be removed whenever the crop is harvested by big machinery [24]. This paper also aims to develop the solution with the help of UGV so that it reduces the manpower required for irrigation thereby overcoming the problem of shortage of workforce in the agricultural sector.

The paper is divided into sections, where Section 3 deals with the methodology adopted in solving the problem. Later, the result is discussed in Section 4, followed by conclusions and future work in Section 5.

\section{METHODOLOGY}

Maintaining an optimum level of water and irrigating the paddy field with the right amount is very important to increase the yield of paddy. To perform this task a smart irrigation system for paddy field is important. The main challenges in developing a smart irrigation system for the paddy field are as follows.

\section{- Collection of sensor data.}

- Implementing the irrigation solution in the paddy field.

\section{A. Collection of Sensor Data}

Collection of data such as real-time field water level, rain status, temperature, humidity in the paddy field has many challenges because of the harsh condition in the paddy field. The method of placing a network of sensors as done in nurseries [25] will not work in particular to the paddy field, as the paddy field is exposed to heavy machinery for ploughing, transplanting, harvesting etc. Placing a network of a wireless sensor for measuring water level, rainwater, humidity, temperature, the light intensity is a big challenge. Instead of reducing the labour cost, this will lead to more cost of labour because the sensor nodes must be removed and placed each time when heavy machinery is used on the field. To solve this problem, the method adopted here is to divide the paddy field into sections and use a UGV which carries sensors on it, to move around in the paddy field collecting data. This not only solves the problem of placing sensor but also reduces the number of sensors needed, thereby reducing the cost, and making this method more feasible and reliable. The description of the sensors used is listed in Table I.

TABLE I. SENSORS USED IN IOT PADDY IRRIGATION SYSTEM

\begin{tabular}{|l|l|l|}
\hline SN & Name & Description \\
\hline 1 & DHT22 & $\begin{array}{l}\text { This sensor uses thermistor and capacitive } \\
\text { humidity sensor to measure the temperature and } \\
\text { humidity of the surrounding air respectively. }\end{array}$ \\
\hline 2 & LDR & $\begin{array}{l}\text { It is a light-sensitive device whose resistivity is a } \\
\text { function of the incident electromagnetic radiation. }\end{array}$ \\
\hline 3 & $\begin{array}{l}\text { Water level } \\
\text { sensor }\end{array}$ & $\begin{array}{l}\text { This sensor gives an analogue signal that depends } \\
\text { on the conductance which varies with the water } \\
\text { level. Its outputs value varies between 0 to 1024. }\end{array}$ \\
\hline 4 & $\begin{array}{l}\text { Raindrop } \\
\text { sensor }\end{array}$ & $\begin{array}{l}\text { In this sensor, as the raindrops fall on the circuit } \\
\text { board, it creates a path of parallel resistance which } \\
\text { is measured using op-amp. }\end{array}$ \\
\hline
\end{tabular}

B. Implementing the Irrigation Solution in the Paddy Field

The method implemented here is developed to reduce the required manpower in paddy cultivation and thereby reducing the cost and thus helping the farmer. Paddy irrigation is laborintensive, as it requires the farmer to constantly check the water level in different sections of the paddy field and maintain the optimal water level in each section, by operating the valves in each section. These works can be achieved by adopting a mobile application-based method and by using an independent cloud-based method.

1) Mobile application-based method: In this method, a mobile application acts as one place switch to monitor the paddy field water level. The mobile application is used to regulate the water level in the field by remotely operating the valves in different sections. Thereby, greatly helping the farmer by reducing the time for operating the valves and directing the water flow in the paddy field. A flow chart representing the mobile application- based method is shown in Fig. 1. In this, the farmer first inputs the login credentials in the mobile application. After logging in, the farmer will be given the option of controlling either the UGV or the water valve. In the UGV control screen, the farmer can control the UGV to move left, right, forward, backward. The UGV moves as instructed and sends the sensor data to the mobile application, where the farmer can see the water level at that location. In the water valve control screen, the farmer can switch the valve on or off.

2) Independent cloud-based method: A flow chart representing the independent cloud-based method is shown in Fig. 2. In this method, the cloud acts as the central system coordinating with the local server and pushing notifications to the mobile application for farmers. The UGV carrying the sensors will be controlled by a local server, the local server then collects the data from the UGV, processes the data and stores it. The local server then updates the variables in the 
cloud database, based on this the cloud platform will switch the valve on or off. Thereby, maintaining an optimal level of water at all times. At the end of each day, the local server also pushes the day's sensor data to the cloud storage.

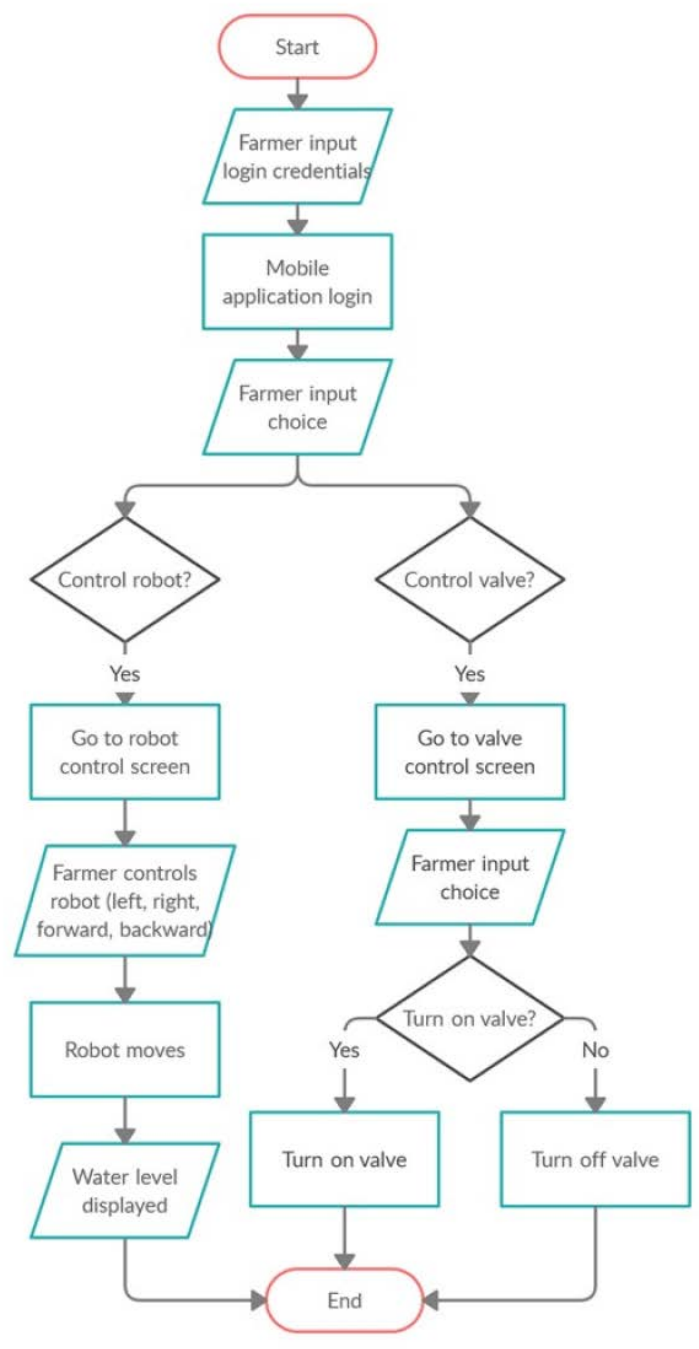

Fig. 1. Flowchart of the Mobile Application-based Method.

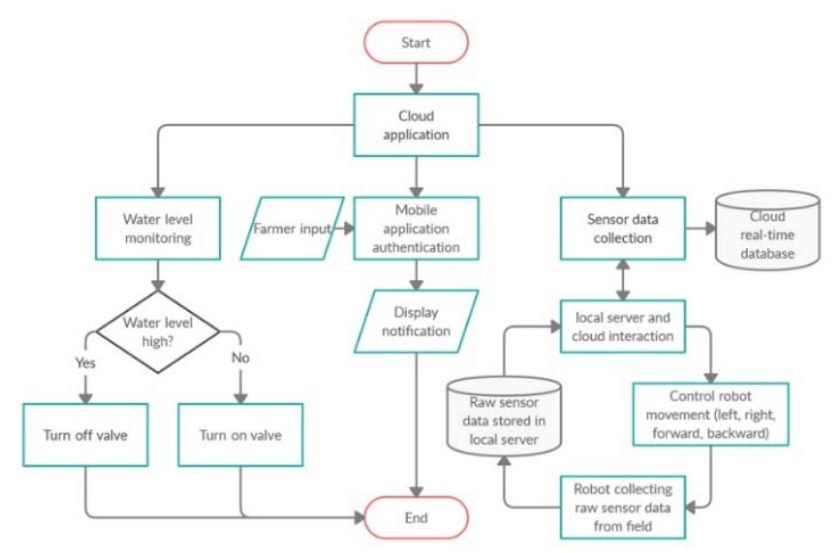

Fig. 2. Flowchart of the Independent Cloud-based Method.

\section{RESUlt AND DisCUSSION}

To develop an IoT solution for the problems faced by the farmers in paddy cultivation. It has been identified that the key to increasing the paddy crop yield, is to closely monitor the water level in the field and irrigate the land with the correct amount of water at various stages of the paddy growth. As a result, the authors have primarily focused on five main components to achieve this goal and they are listed below:

- Water level monitoring system.

- Water Valve system.

- Unmanned Ground Vehicle.

- Mobile application-based solution.

- Independent cloud-based solution.

On the road to developing a solution, some more hardware components that were used are listed in Table II. The description of each component of the solution that was developed is discussed in the following sub-sections.

TABLE II. SOME MORE COMPONENTS USED IN IOT PADDY IRRIGATION SYSTEM

\begin{tabular}{|l|l|l|}
\hline SN & Name & Description \\
\hline 1 & Arduino UNO & $\begin{array}{l}\text { It is a microcontroller having 6 analogue input } \\
\text { pins and 14 digital input/output pins. }\end{array}$ \\
\hline 2 & $\begin{array}{l}\text { Raspberry Pi 3 } \\
\text { Model B+ }\end{array}$ & $\begin{array}{l}\text { It is a single-board computer with wireless, } \\
\text { LAN and Bluetooth connectivity. }\end{array}$ \\
\hline 3 & $\begin{array}{l}\text { Node } \\
\text { Microcontroller } \\
\text { Unit (Node MCU) }\end{array}$ & $\begin{array}{l}\text { It is a microcontroller having low-cost open- } \\
\text { source firmware and board based on the eLua } \\
\text { project. }\end{array}$ \\
\hline 4 & ESP8266 & $\begin{array}{l}\text { It is a low-cost Wi-Fi microchip with } \\
\text { microcontroller capability and a full TCP/IP } \\
\text { stack. }\end{array}$ \\
\hline 5 & $\begin{array}{l}\text { L293d IC motor } \\
\text { driver }\end{array}$ & $\begin{array}{l}\text { It is a Motor Driver module which can control } \\
\text { the speed and direction of two motors } \\
\text { simultaneously. }\end{array}$ \\
\hline 6 & Relay Module & $\begin{array}{l}\text { It can be controlled with low voltage. It is an } \\
\text { electrically operated switch which allows the } \\
\text { current to pass through when turned on. }\end{array}$ \\
\hline 7 & Solenoid valve & $\begin{array}{l}\text { It is an electromechanically controlled valve } \\
\text { which consists of a solenoid and a movable } \\
\text { ferromagnetic core in its centre. }\end{array}$ \\
\hline
\end{tabular}

A. Water Level Monitoring System

Water is a very important natural resource; water is the lifeline for any agricultural activity. The scarcity of water resources in many countries has forced everyone to look for means of utilizing the water resource with utmost care [26]. To utilize the water resources fruitfully, it is necessary to provide the right amount of water for agricultural activity, especially for the cultivation of water demanding crops like paddy, which calls for the need of good water management system for paddy cultivation. The best way to have good water management system is to have a good water level monitoring system.

In paddy cultivation, water plays a vital role in proper yield, as water can both be constructive (i.e., more yield) and destructive (i.e., poor yield). Too less water may lead to dying of crops and cracking of land. Very high water may lead to a poor yield of paddy, it may also lead to the soil nutrients being washed out and causes soil salinity. Therefore, water level 
monitoring is crucial for paddy cultivation. The paddy cultivation always requires standing water. This standing water needs to be at different levels in different stages of the paddy life cycle which is obtained from [27]. Therefore, it is very important to check the paddy field water level at various stages of its life cycle.

To monitor the paddy field, the water level sensor is used. The water level sensor is connected to the Arduino UNO via an analogue input pin. The sensor measures the water level and gives output in the form of analogue signals which varies from 0 to 1024 , which is mapped to 0 to 5 centimeter of water level in the Arduino using proportionality relation (1). This measurement is then taken consecutively for 20 times in one location and then averaged to get the most accurate value of water level at that location. In this way, the water can be monitored most accurately. Fig. 3 gives the pictorial representation of the water level monitoring system.

water level $(\mathrm{cm})=\frac{\text { analog pin input } * 5}{1023}$

\section{B. Water Valve System}

Valves are very important for the controlled flow of water. In the agriculture field, valves are vital for controlling, stopping, and directing the water flow for irrigation. Valves play the role of end actuator by working as the output device for the input from a water level monitoring system. The water level monitoring system acts as the sensing system in the irrigation of paddy fields.

As paddy fields are very large, it is usually divided into many small sections by constructing bunds. Water is then directed to each of the sections by opening a small portion of the bunds when the required level of water is reached. The portion of the bunds is closed, and other sections are irrigated in the same way. This involves a lot of manpower and wastage of precious time of the farmers. This can otherwise be directed to other important agricultural activities such as weeding, fertilizing process etc., it also leads to excess or low water being irrigated which may lead to a lower yield of paddy. Hence this loss of time and money the farmer and the poor yield can be prevented by using a valve system that is remotely operated either by mobile application or by cloud services.

To develop this valve system a low-cost solenoid valve is used. This valve is connected to the Relay module which is controlled by Node MCU as shown in Fig. 4. Node MCU receives a signal from either the mobile application or cloud platform to switch on or off the valve, and then the MCU switches the relay module which then leads to the opening or closing the valve. In this way, the exact level of water given by [27] in the paddy field is maintained.

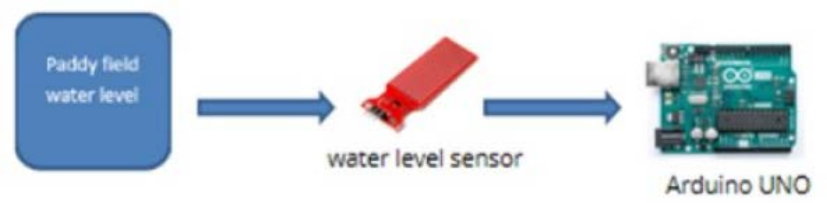

Fig. 3. Pictorial Representation of the Water Level Monitoring System for Paddy Cultivation.

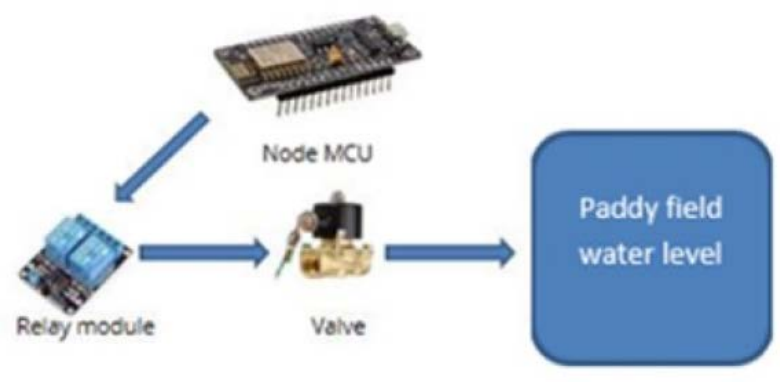

Fig. 4. Pictorial Representation of the Valve System for Paddy Cultivation.

\section{Unmanned Ground Vehicle}

Paddy field has harsh conditions that are not suitable for sensors, hence the sensors must be protected, it also poses the challenge of placing the sensors in the right locations, to get an accurate reading. Placing the sensors on the ground at a different location to monitor water level, temperature, humidity etc. will not be suitable for paddy field because of various difficulties involved. Hence, there is a need for a robot to carry sensors. As our primary objective is to measure the water level, aerial robots will not serve the purpose, as it is not possible to measure the water level on the paddy field from air. Hence a UGV was developed for this purpose.

The UGV was designed to face the challenges in the paddy field. The design procedure consisted of first identifying the difficulties the UGV would face such as muddy, slippery soil, water standing up to a level. Then various sensors that the UGV must carry was considered, motor's speed to drive the UGV, the battery size, the weight of all the components were considered. The chassis of the UGV was designed considering all these factors. The material was assigned as aluminum because of its lightweight property, as the weight was a major factor in design. As the weight increases, the motor size increases, and the battery size should have to be increased. The wheel of the UGV was decided to be a tracked wheel since it provides a large surface area. Computer-Aided Drawing (CAD) software 'Solid Edge' was used to visualize each part of the chassis. Later all the parts were assembled in the CAD software, shown in Fig. 5. Then based on the CAD software visualization, a model was built.

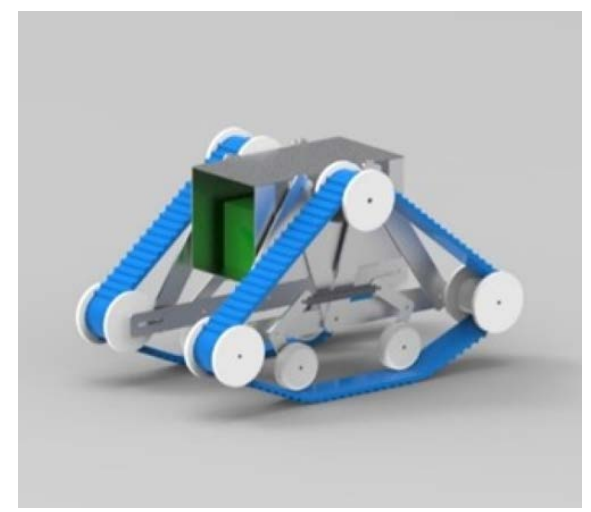

Fig. 5. Picture of UGV Assembled in CAD Software Solid Edge. 
The UGV is driven by two DC motor, with the help of L293d IC motor driver which is controlled by Arduino UNO. The UGV carries sensors DHT22 (Humidity and temperature sensor), water level sensor, raindrop sensor, LDR. The pictorial representation of all the sensors carried by the UGV is shown in Fig. 6 and the model of the UGV after fabrication is shown in Fig. 7.

\section{Mobile Application-based Solution}

The smartphone industry is a growing market in the world, with more and more smartphones penetration into developing country like India, it is expected to reach a user base of 442 million by 2022 [28]. Hence, it has been identified that mobile application-based solution to be a feasible solution for the problem of irrigation [29].

There are lots of work involved in irrigating a paddy field such as, constantly checking the water level in different sections of the paddy field, making sure that the water is maintained at the correct level in each section, opening and closing the valves and directing the water to all the sections. This may not be a big problem for a very small field, but for a very large field, it is very time consuming and may even require a separate full-time worker just for performing these tasks. Employing a separate worker just to perform these tasks incurs additional expenditure to the farmer which can otherwise be prevented by employing technology. Hence the use of a smartphone with a mobile application to perform these tasks will help reduce the unwanted expenditure in employing workers.

The mobile application is a web-based application which is hosted by Google's Firebase. It has three functionalities they are,

- Operate the UGV that carries the sensor.

- Switching on or off the valves.

- Receive any notifications from the cloud platform.

The mobile application has a login screen which requires an email id and password to $\log$ in. The credentials are authenticated by the Google firebase's authentication, where it assigns Unique Identification (UID) for each user hence the details of the farmers are stored securely. It has a screen for receiving the notification regarding updates on the field and other related news such as government schemes, which is shown in Fig. 8, firebase has the option of pushing a userspecific notification by using UID that is assigned to each user.

The mobile application has a screen for operating the UGV, where there is information regarding the water level at the current location of UGV and it has buttons for maneuvering the UGV left, right and to move forward, backward and stop. It also has a button for switching the mode of the UGV control to the mobile application-based method or independent cloudbased method. It has another screen which has buttons for switching the valves on and off, this is shown in Fig. 9.

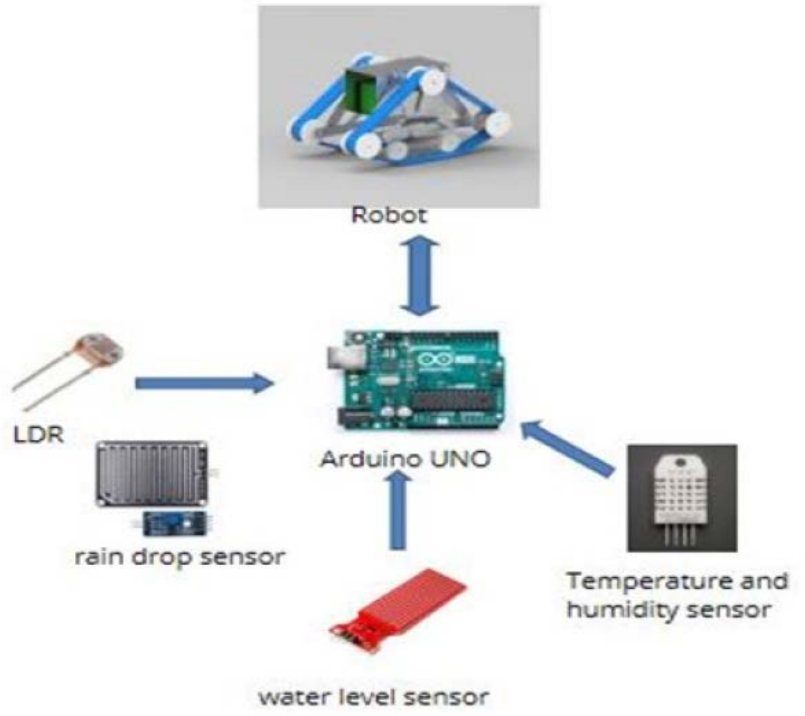

Fig. 6. Pictorial Representation of all the Sensors Carried by the UGV.

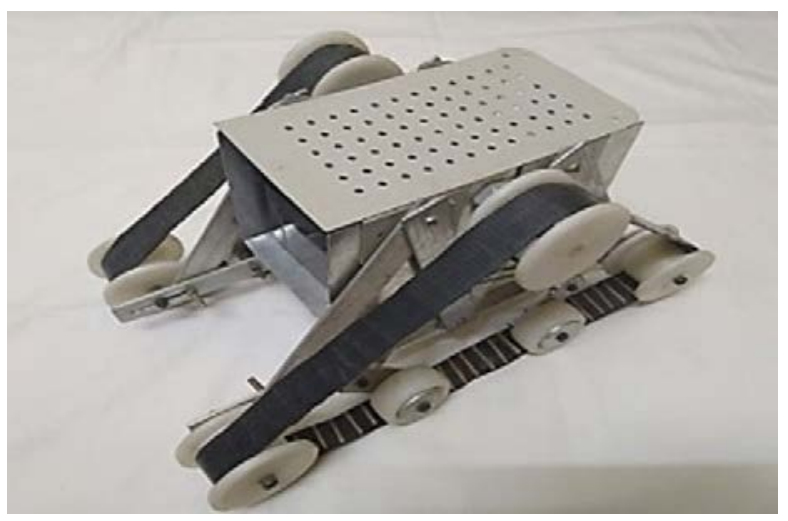

Fig. 7. The Model of the UGV after Fabrication.
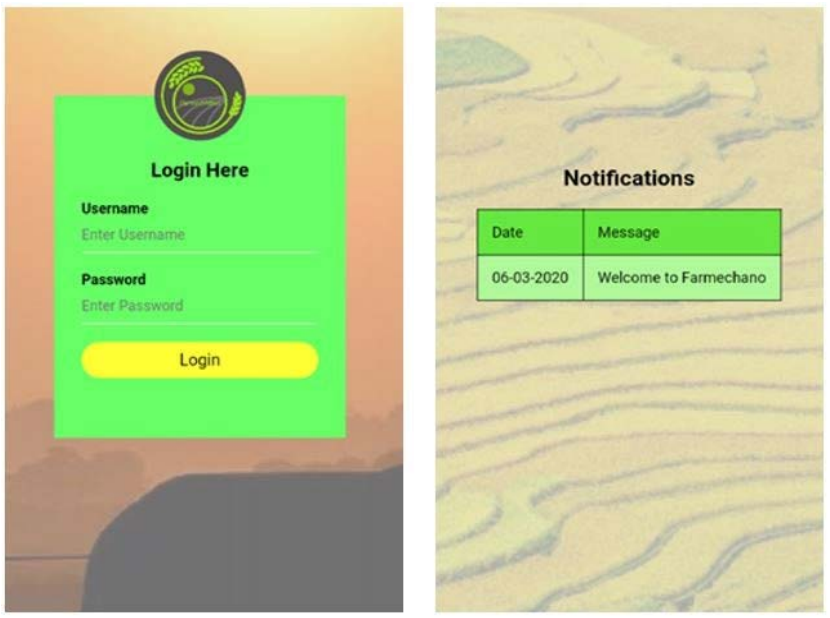

Fig. 8. Snapshot of Login Screen towards Left and Notification Screen towards the Right of Mobile Application. 

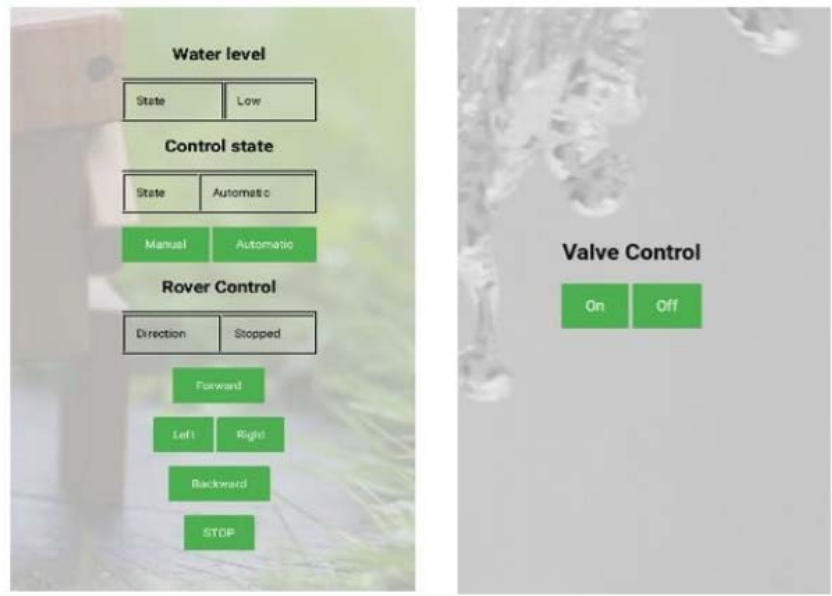

Fig. 9. Snapshot of the Screen for UGV Control in the Left and Screen of Valve Control in the Right in the Mobile Application.

A pictorial representation of a mobile application-based control system is shown in Fig. 10. In this when the buttons in the mobile application are pressed, the corresponding variable of the UGV in Google's Firebase real-time database is updated. These variables, which is constantly being monitored by the local server (Raspberry Pi) as well as the Node MCU of the valve control system receives the command. The local server then sends this command to the UGV using Wi-Fi as the channel for communication. The UGV receives this command with the help of ESP8266 connected to the Arduino Uno. Based on the command, the Arduino controls the driving motor, on the other hand, the Node MCU of the valve control system controls the valve based on the command.

\section{E. Independent Cloud-based Solution}

Paddy cultivation is labour intensive, a decrease of workers available for agricultural activity has become a major problem in recent years. As more and more agricultural labourers are migrating to cities in search of better livelihood, financial and social status [30]. This has risen an alarm in the agricultural sector, as farmers are not getting sufficient labourers to carry out agricultural activities. The poor income of farmers and the rising cost of labourers for agricultural activities, has also become a concern. Hence this problem can be solved by bringing in automation in the cultivation of paddy field and integrating with the cloud to develop an end-to-end IoT solution.

The main objective of an independent cloud-based system is listed below:

- To monitor the water level of the paddy field

- To control the UGV for collecting paddy field data

- To control the water level of the paddy field

- To store the collected sensor data

The pictorial representation of the independent cloud-based control system is shown in Fig. 11. In this Raspberry Pi is employed, which is the local server placed in the storeroom next to the paddy field which is considered as the control room. The local server further divides the sections of the paddy fields created by constructing bunds into small pieces virtually, it then instructs the UGV which carries the water level monitoring system on it, to move towards each of these sections and carry out the reading, the water level monitoring system along with various other sensors attached to the UGV (as discussed in section IV C) sends the readings to the local server through Wi-Fi. The local server then processes these raw sensor data and stores the values in the local variables such as water level, temperature, humidity, light intensity, rain. The local server then compares the values for water level with the predefined values which are recommended by the Tamil Nadu Agricultural University (TNAU) where the optimal level of water for different stages of the paddy crop growth can be obtained for different ecosystems [27]. The value of variable water level (wat lev) in each section of the paddy field, temperature (temp), humidity (hum), rain, light intensity (LDR) of the field as processed and displayed by the local server is shown in Fig. 12.

The local server then logs all the processed sensor data in a local file of .CSV format which has columns of time, water level, LDR, rain, humidity, temperature, for every one-hour. This .CSV file is then uploaded to Google firebase's Fire-store at the end of each day, which can later be used for checking the health of various sensors.

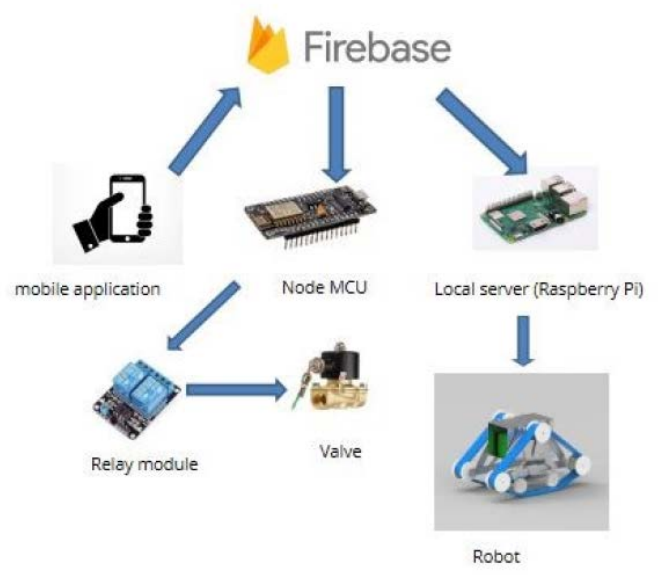

Fig. 10. Pictorial Representation of the Mobile Application-based Control System.

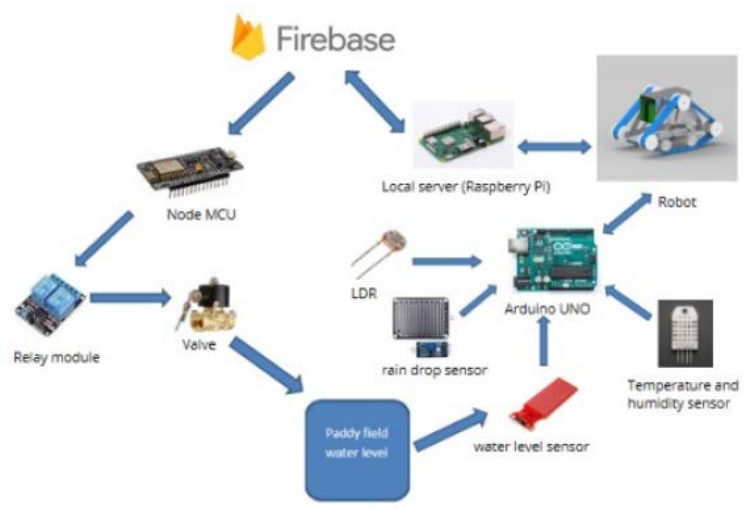

Fig. 11. Pictorial Representation of the Independent Cloud-based Control System. 


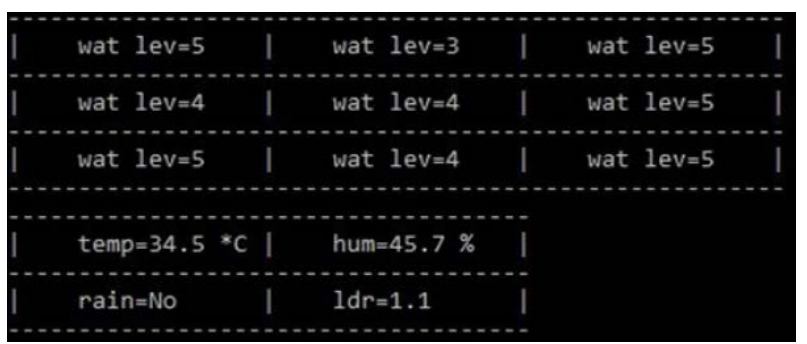

Fig. 12. Snapshot of the Local Variable Values of Water Level for each Section of the Paddy Field along with Temperature, Humidity, Rain Status,

Light Intensity (LDR) as Processed and Displayed by the Local Server.

The water level and rain status are updated on the respective variable in Google's firebase real-time database. Based on the water level and rain status the firebase updates the variable 'valve' in the firebase Realtime database. This variable 'valve' being monitored by the valve system controls the valves for various sections of the paddy field. Thus, the independent cloud-based solution can monitor and control the water level of the paddy field.

As mentioned earlier, to increase the paddy crop yield monitoring the water level and irrigating the paddy field with the right amount of water at a different stage of the paddy growth is important. First, the water level that was maintained in a paddy field by following the traditional method of irrigation, where farmers direct the flow of water to different sections manually and maintain water level by eye judgment was recorded, for each hour of the day from 06:30 Hrs. to 18:30 Hrs. Then water level that was maintained in the paddy field by following a mobile application-based solution was recorded for each hour of the day from 06:30 Hrs. to 18:30 Hrs. Then water level that was maintained in the paddy field by following independent cloud-based solution was recorded for each hour of the day from 06:30 Hrs. to 18:30 Hrs. Then the water level values that were collected by using all three methods were plotted against time of the day as shown in Fig. 13. The optimum water level is represented by a constant line in the graph.

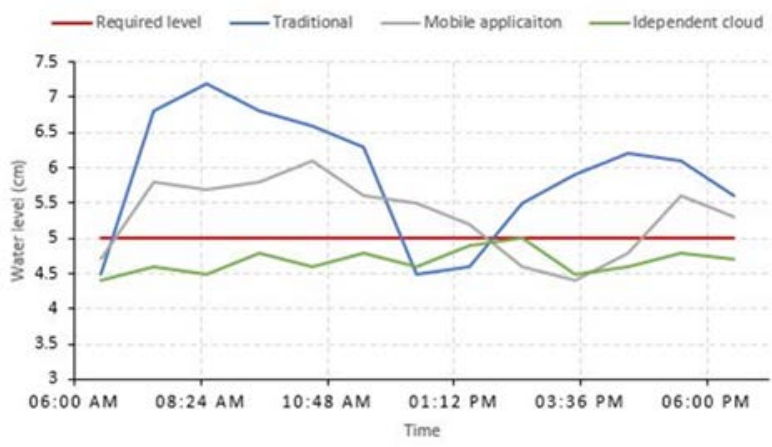

Fig. 13. A Plot of Water Level in cm vs Time for various Methods followed for Paddy Cultivation.

From the graph, the independent cloud-based solution could maintain the water level in the paddy field at a nearconstant required level when compared to the mobile application-based solution and traditional method. It was observed that in the traditional method, farmers tend to use more water than recommended since they have no means to measure the exact level of water and just go by eye perspective, whereas when using the mobile application-based solution, there is means to know the water level, thereby the water level is fairly close to the recommended level but there are large deviations a time, as it is still operated by a human.

\section{CONCLUSION AND FUTURE WORK}

A novel solution for irrigation of paddy field was presented with Unmanned Ground Vehicle (UGV) and Internet of Things (IoT) by investigating various problems arising in placing sensors in the paddy field. This solution enables maintaining the water level in the paddy field in the optimal level which is an important parameter for a good yield of paddy crop, throughout the growth cycle in the most cost-effective manner. The solution presented in this paper is feasible to integrate into the present paddy field with ease. It also helps in saving the time and manpower required for paddy cultivation. The solution presented here can be used in places where water resources are scarce and stringent monitoring of water is required. It minimizes the wastage of water and thereby conserving the precious water resources. The UGV can further be modified to carry and spray pesticides, fertilizers etc. making it a multirole UGV for use in paddy field. The path planning for the UGV can be made more dynamic by implementing machine learning and artificial intelligence. The solution developed here can be modified and tested for use in other type of crops.

\section{REFERENCES}

[1] Aazam, Mohammad, Sherali Zeadally, and Khaled A. Harras. "Deploying fog computing in industrial internet of things and industry 4.0." IEEE Transactions on Industrial Informatics 14, no. 10 (2018): 4674-4682.

[2] Sanchez, Luis, Luis Muñoz, Jose Antonio Galache, Pablo Sotres, Juan R. Santana, Veronica Gutierrez, Rajiv Ramdhany et al. "SmartSantander: IoT experimentation over a smart city testbed." Computer Networks 61 (2014): 217-238.

[3] Sastra, Nyoman Putra, and Dewa Made Wiharta. "Environmental monitoring as an IoT application in building smart campus of Universitas Udayana." In 2016 International Conference on Smart Green Technology in Electrical and Information Systems (ICSGTEIS), pp. 8588. IEEE, 2016.

[4] Park, Eunil, Yongwoo Cho, Jinyoung Han, and Sang Jib Kwon. "Comprehensive approaches to user acceptance of Internet of Things in a smart home environment." IEEE Internet of Things Journal 4, no. 6 (2017): 2342-2350.

[5] Islam, SM Riazul, Daehan Kwak, MD Humaun Kabir, Mahmud Hossain, and Kyung-Sup Kwak. "The internet of things for health care: a comprehensive survey." IEEE access 3 (2015): 678-708.

[6] Li, Lin. "Application of the internet of thing in green agricultural products supply chain management." In 2011 Fourth International Conference on Intelligent Computation Technology and Automation, vol. 1, pp. 1022-1025. IEEE, 2011.

[7] Husni, Emir, Galuh Boy Hertantyo, Daniel Wahyu Wicaksono, Faisal Candrasyah Hasibuan, Andri Ulus Rahayu, and Muhamad Agus Triawan. "Applied Internet of Things (IoT): car monitoring system using IBM BlueMix." In 2016 International Seminar on Intelligent Technology and Its Applications (ISITIA), pp. 417-422. IEEE, 2016.

[8] Stankovic, John A. "Research directions for the internet of things." IEEE internet of things journal 1, no. 1 (2014): 3-9.

[9] Tzounis, Antonis, Nikolaos Katsoulas, Thomas Bartzanas, and Constantinos Kittas. "Internet of Things in agriculture, recent advances and future challenges." Biosystems engineering 164 (2017): 31-48.

[10] Crop production and natural resource use: http://www.fao.org/3/ y4252e/y4252e06.htm. 
[11] Population: https://www.un.org/en/global-issues/population

[12] Maclean, Jay L., David Charles Dawe, and Gene P. Hettel, eds. Rice almanac: Source book for the most important economic activity on earth. Int. Rice Res. Inst., 2002.

[13] Balasubramanian, V., M. Bell, and M. Sombilla. "Yield, profit, and knowledge gaps in rice farming: Causes and development of mitigation measures." BRIDGING THE RICE YIELD GAP IN THE ASIAPACIFIC REGION (2000): 163.

[14] Number of smartphone users worldwide from 2016 to 2021 (in billions): https://www.statista.com/statistics/330695/number-of-smartphone-usersworldwide/

[15] Singh, S., T. F. Burks, and W. S. Lee. "Autonomous robotic vehicle development for greenhouse spraying." Transactions of the ASAE 48, no. 6 (2005): 2355-2361.

[16] Sammons, Philip J., Tomonari Furukawa, and Andrew Bulgin. "Autonomous pesticide spraying robot for use in a greenhouse." In Australian Conference on Robotics and Automation, vol. 1, no. 9. 2005.

[17] Yaghoubi, Sajjad, Negar Ali Akbarzadeh, Shadi Sadeghi Bazargani, Sama Sadeghi Bazargani, Marjan Bamizan, and Maryam Irani Asl. "Autonomous robots for agricultural tasks and farm assignment and future trends in agro robots." International Journal of Mechanical and Mechatronics Engineering 13, no. 3 (2013): 1-6.

[18] Bogue, Robert. "Robots poised to revolutionise agriculture." Industrial Robot: An International Journal (2016).

[19] Brown, K. W., F. T. Turner, J. C. Thomas, L. E. Deuel, and M. E. Keener. "Water balance of flooded rice paddies." Agricultural Water Management 1, no. 3 (1977): 277-291.

[20] Kaewmard, Nattapol, and Saiyan Saiyod. "Sensor data collection and irrigation control on vegetable crop using smart phone and wireless sensor networks for smart farm." In 2014 IEEE Conference on Wireless Sensors (ICWiSE), pp. 106-112. IEEE, 2014.

[21] Abhijith, H. V., Darpan A. Jain, and U. Adithya Athreya Rao. "Intelligent agriculture mechanism using internet of things." In 2017
International Conference on Advances in Computing, Communications and Informatics (ICACCI), pp. 2185-2188. IEEE, 2017.

[22] Lea-Cox, John D., George F. Kantor, and Andrew G. Ristvey. "Using wireless sensor technology to schedule irrigations and minimize water use in nursery and greenhouse production systems." In Comb. Proc. Int. Pl. Prop. Soc, vol. 58, pp. 512-518. 2008.

[23] Xiao, Kehui, Deqin Xiao, and Xiwen Luo. "Smart water-saving irrigation system in precision agriculture based on wireless sensor network." Transactions of the Chinese society of Agricultural Engineering 26, no. 11 (2010): 170-175.

[24] Muazu, A., A. Yahya, W. I. W. Ishak, and S. Khairunniza Bejo. "Machinery utilization and production cost of paddy cultivation under wetland direct seeding conditions in Malaysia." Engineering in agriculture, environment and food 8, no. 4 (2015): 289-297.

[25] Coates, Robert W., Michael J. Delwiche, Alan Broad, and Mark Holler. "Wireless sensor network with irrigation valve control." Computers and electronics in agriculture 96 (2013): 13-22.

[26] García, Laura, Lorena Parra, Jose M. Jimenez, Jaime Lloret, and Pascal Lorenz. "IoT-based smart irrigation systems: An overview on the recent trends on sensors and IoT systems for irrigation in precision agriculture." Sensors 20, no. 4 (2020): 1042.

[27] Expert system for paddy: http://www.agritech.tnau.ac.in/ expert_system/paddy/cultivationpractices3.html

[28] Number of smartphone users in India: https://www.statista.com /statistics/467163/forecast-of-smartphone-users-in-india/

[29] Saad, Abdelmadjid, and Abdoulaye Gamatié. "Water management in agriculture: A survey on current challenges and technological solutions." IEEE Access 8 (2020): 38082-38097.

[30] Doddamani, K. N. "A study on migration of agriculture labourers from hyderabad Karnataka area to Maharashtra." IOSR-JHSS 19 (2014): 6871. 